\title{
A study of sensitivity to curare in myasthenic disorders using a regional technique
}

\author{
J. COLIN BROWN ${ }^{1}$ AND J. EDMOND CHARLTON
}

From the Departments of Anaesthesia and Neurology, Royal Victoria Infirmary, Newcastle upon Tyne

SYNOPSIS A study of curare sensitivity has been made in ocular myasthenia, myasthenia gravis, and the myasthenic syndrome sometimes associated with carcinoma, using a regional technique. Sensitivity is greater than in normal subjects. The injection of $0.125 \mathrm{mg}$ d-tubocurarine resulted in a neuromuscular transmission block in all but a few of those cases with ocular myasthenia and in all cases of generalized myasthenia. Furthermore, the block persisted for longer than in normal subjects after the release of the tourniquet. This sensitivity to curare was not directly related to myasthenic weakness. The reasons for this are discussed and an explanation for such curare sensitivity is suggested.

Undue sensitivity to curare is a recognized feature of myasthenic disorders and has been used as a diagnostic tool in myasthenia gravis (Bennett and Cash, 1943; Pelikan et al., 1953; Grob et al., 1956). The survey of Rowland et al. (1961) showed that excessive sensitivity was always found in generalized myasthenia gravis and occurred also in a proportion of patients with ocular myasthenia. It is of interest that the weakest muscles were not always the most sensitive and undue sensitivity was sometimes found in latent myasthenia with no weakness at the time of study.

In such studies, interpretation relied upon clinical observation so that 'faulty observations, malingering and suggestion may lead to falsely positive results' (Rowland et al., 1961).

A regional method for measuring curare sensitivity, described in a previous paper (Brown et al., 1975) was therefore undertaken in patients with myasthenic disorders. A much smaller dose of d-tubocurarine could be given and, since neuromuscular stimulation is used, there is no need for voluntary muscle contraction, a possible source of error. Furthermore, the recording of muscle action potentials (MAP) evoked by trains of stimuli yields more detailed information

1 Present address: Norfolk and Norwich Hospital, Norwich, Norfolk, NR1 3SR. about changes in neuromuscular transmission in this situation.

\section{METHODS}

The subjects were 11 patients with generalized myasthenia gravis, 10 patients with ocular myasthenia, and two patients with the myasthenic syndrome sometimes associated with carcinoma (EatonLambert syndrome). The patients with myasthenia gravis took their usual dose of anticholinesterase drugs on the day of investigation. The clinical details are outlined in Table 1.

The methods used and precautions taken were identical to those described in the study of normal subjects (Brown et al., 1975) but as the dosage of d-tubocurarine used in normal subjects $(0.5 \mathrm{mg})$ would cause so great a block in neuromuscular transmission in myasthenic subjects that in most instances the evoked MAP would be no longer recordable, a dosage of $0 \cdot 125 \mathrm{mg}$ was used. This enabled differences in sensitivity to be discerned amongst the myasthenic subjects.

\section{RESULTS}

These are summarized in the Table and in Figs 1 and 2. Among the patients with ocular myasthenia, two were resistent to the dose given, three showed only a slight response, while five developed a significant persisting block of neuro- 


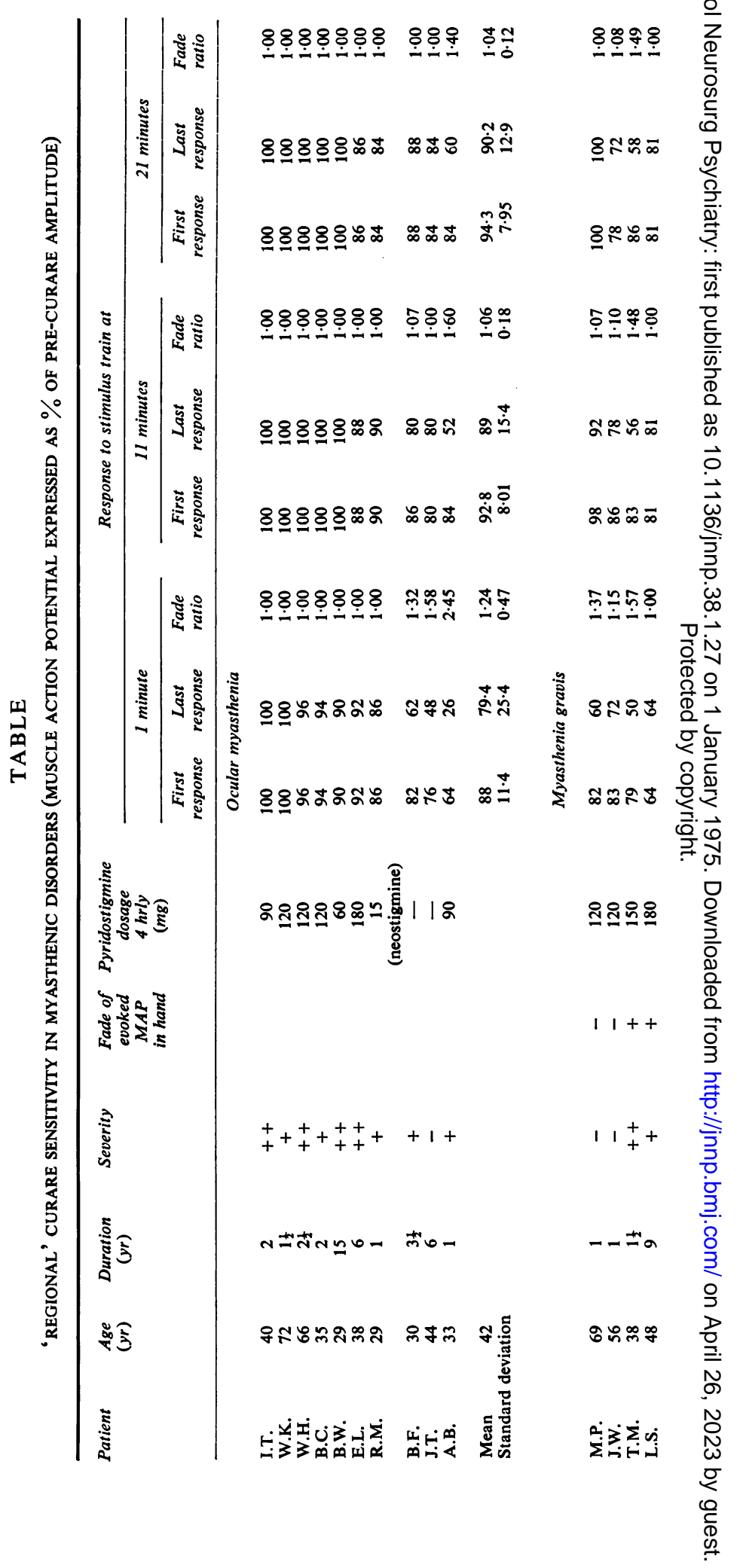




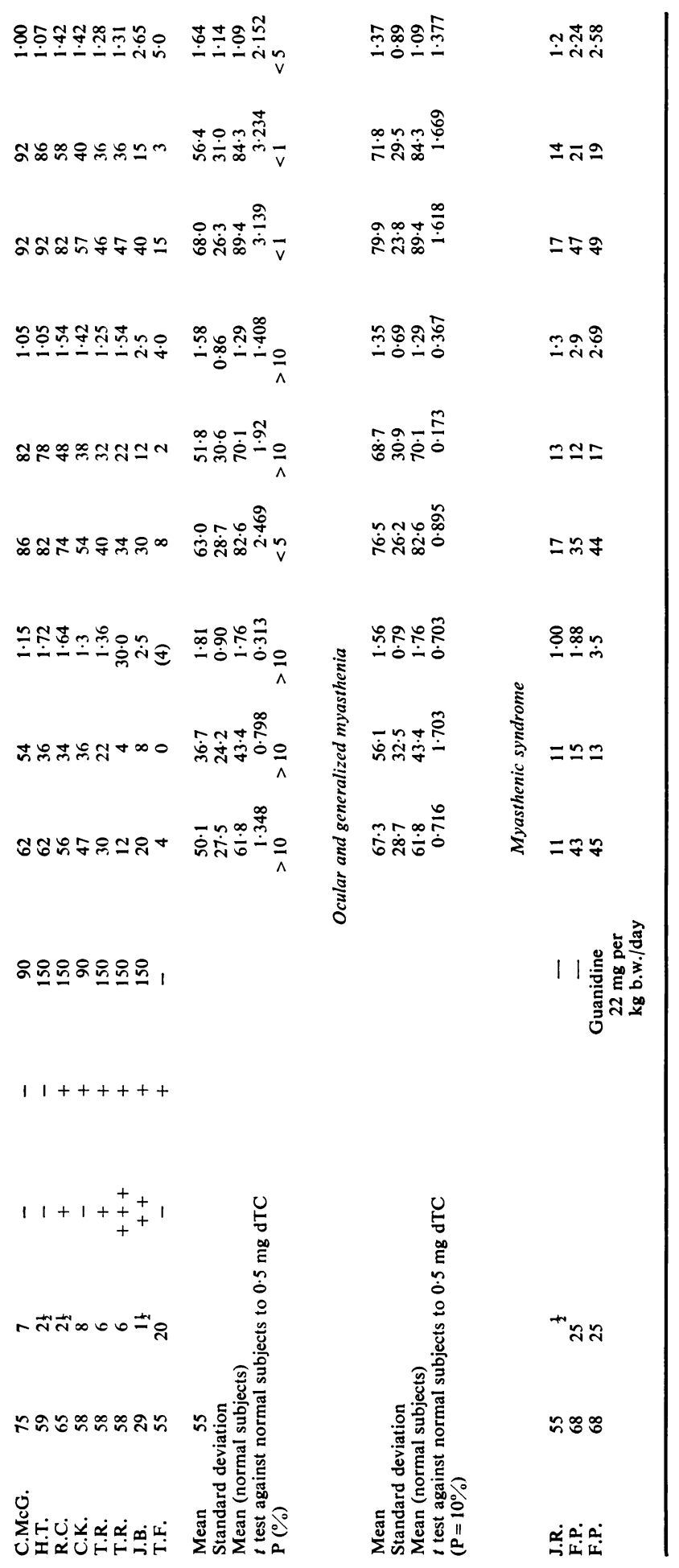


Ocular Myasthenia

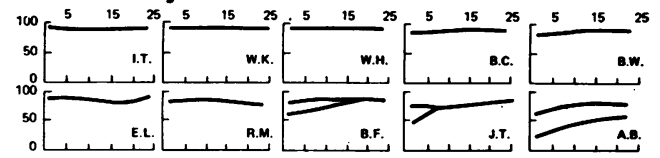

\section{Generalised Myasthenia}

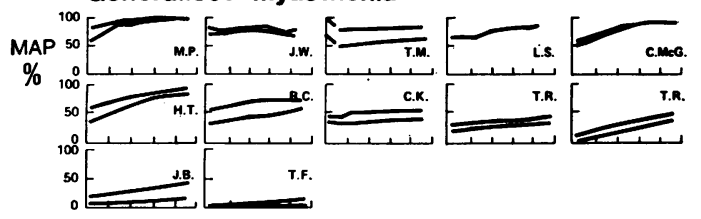

FIG. 1. Effect of the 'regional' injection of $0.125 \mathrm{mg}$ $d$-tubocurarine in myasthenic disorders (see text).

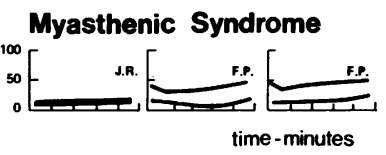

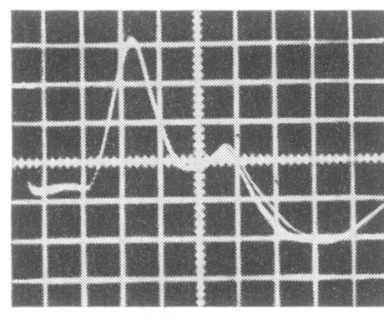
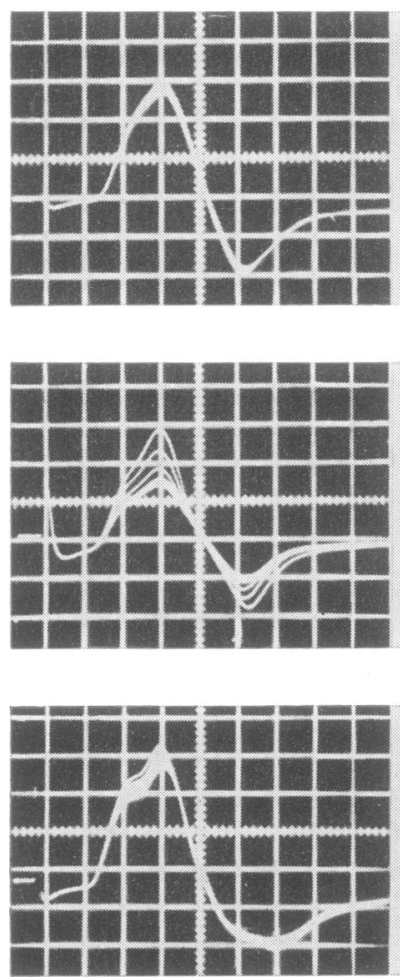
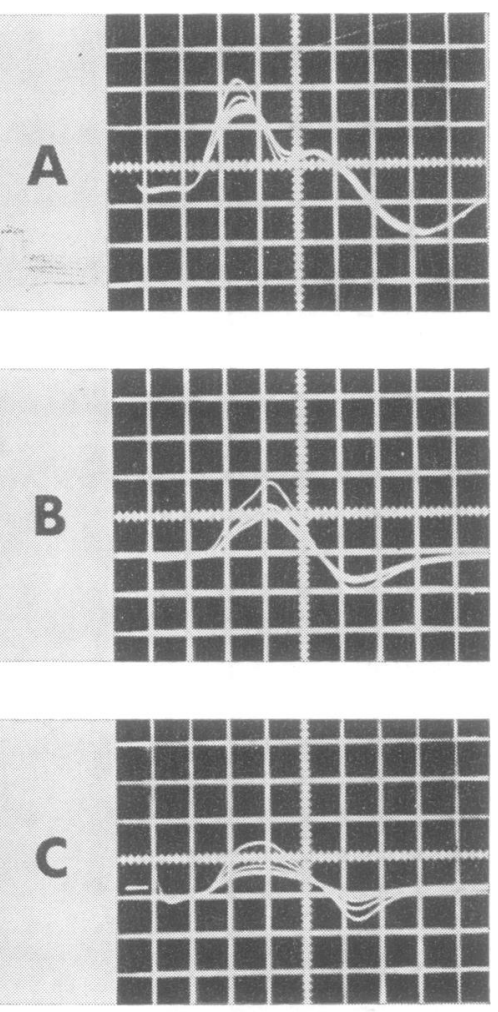

FIG. 2. Examples of curare sensitivity in different myasthenic disorders. Recordings of superimposed muscle action potentials evoked by the stimulus train. In each: on the left, before injection; on the right, after $0.125 \mathrm{mg}$ d-tubocurarine. A: B.F., ocular myasthenia. B: R.C., generalized myasthenia. C: F.P., myasthenic syndrome. D: T.F., latent myasthenia. Vertical divisions: $\mathrm{A}, \mathrm{B}$, and $\mathrm{D}, 2 \mathrm{mV}$. C: $1 \mathrm{mV}$. Horizontal divisions: $2 \mathrm{~ms}$. 
muscular transmission which in some instances was comparable with that seen in the subjects with generalized myasthenia gravis.

Among the patients with generalized myasthenia, there was some effect upon neuromuscular transmission in all cases to the dose of $0 \cdot 125$ $\mathrm{mg}$, a quarter of that required to cause a significant reproducible response in the majority of normal subjects. In the combined series of ocular and generalized myasthenia, this dose caused changes not significantly different from those caused by $0.5 \mathrm{mg}$ in normal subjects (Table). In the generalized myasthenia series, the MAP at 11 minutes remained smaller than in normal subjects $(\mathrm{t}=2.47, \mathrm{P}<0.05)$, this difference being even more significant at 21 minutes $(t=3 \cdot 14$, $P<0.05)$.

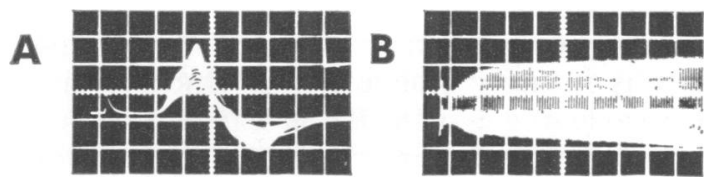

FIG. 3. Patient T.F.: muscle action potential evoked by a 10 second train of nerve stimulation at a frequency of 10 per second. A: superimposed responses, $2 \mathrm{~ms}$ per horizontal division. B: Sequential responses, 1 s per horizontal division, $4 \mathrm{mV}$ per vertical division.

In one patient with the Eaton-Lambert syndrome, the study was repeated after she had commenced treatment with guanidine, $22 \mathrm{mg}$ per $\mathrm{kg}$ body weight per day, which drug increases the amount of acetylcholine released by each nerve impulse (Otsuka and Endo, 1960). This did not significantly affect the curare sensitivity.

In one patient with generalized myasthenia gravis the study was performed both during a clinical remission and in a relapse. There was very little difference in curare sensitivity on each occasion.

\section{DISCUSSION}

In that the dosage of d-tubocurarine differs from that used in normal subjects, a direct comparison of the responses cannot be made. Nevertheless, the fact that the changes induced in myasthenic disorders using a quarter of the dose for normal subjects were in fact greater than the changes induced in such normal subjects is significant. Undue curare sensitivity was found in every case of generalized myasthenia by Rowland et al. (1961). That we have been able to show this in each case in this series shows that this technique is reliable.

Since there will be variations from case to case in perfusion of d-tubocurarine to the neuromuscular junction after its injection, significance cannot be attached to small differences in the MAP immediately after the injection. However, the differences here are great enough to show that neuromuscular transmission is abnormal in myasthenic disorders. There is also extremely slow recovery in patients with marked sensitivity. Binding of the curare at the receptor site (Paton, 1961) might delay recovery, yet, when the concentration of curare falls below a critical level at this site, some improvement in neuromuscular transmission should occur. The release of the tourniquet in our studies must lead to such a fall in concentration due to perfusion with blood containing no curare, yet no such rapid improvement occurs-indeed, the limb may remain weak for some hours.

If 'binding' of curare to the receptor substance preventing access of acetylcholine (Feldman and Tyrell, 1970) alone was responsible for the perpetuation of the block, then a similar rate of recovery might be expected in normal and myasthenic subjects. That this is not the case suggests that the availability of acetylcholine during recovery must be a significant factor. The altered curare sensitivity in myasthenia gravis could therefore be explained on the basis of a prejunctional defect.

The anticholinesterase medication being taken by the patients at the time of their study should affect the response to curare. It was not thought justified to stop this on clinical grounds and the results show that it did not, in fact, mask the undue sensitivity in such patients. Furthermore, there is no correlation between anticholinesterase dosage and the degree of curare sensitivity, though edrophonium (Tensilon) does affect the rate of recovery from the curare-induced block in normal subjects (Brown et al., 1975). Thus, the effect of such medication appears to play little part in the response to curare with this technique. 
The investigation has the following advantages in the study of myasthenic patients: medication need not be stopped; the total dosage of dtubocurarine is small and does not have to be repeated; finally, should a severe block of neuromuscular transmission occur on this dose, the decline in evoked MAP in the hand will give ample warning before the tourniquet is released and the remaining d-tubocurarine enters the systemic circulation.

The dosage used still necessitates precautions against possible respiratory failure. One of our patients, T.F., a very strong man, whose myasthenia had been 'latent' for 15 years, developed an almost complete block of neuromuscular transmission in the hand after the injection and after release of the tourniquet he had transient ptosis, diplopia, and slight breathing difficulty, though not enough to require assisted ventilation.

The latter patient illustrates one of the most interesting aspects of curare sensitivity in myasthenic disorders. A situation may exist where the neuromuscular junction is capable of transmitting impulses to the limit of physiological requirement, yet it is unable to combat the competitive blocking action of curare. Contrariwise, impaired neuromuscular transmission in myasthenia, enough to cause significant weakness and fatigue, is compatible with only slight impairment in the ability to combat the effect of curare.

Extreme sensitivity to curare may exist without symptoms in other disorders. In patients studied with the Eaton-Lambert syndrome, excessive sensitivity was unaccompanied by any weakness or fatigue at the site studied. The neuromuscular transmission findings in patient T.F., who exhibited such marked curare sensitivity with latent myasthenia gravis, are also pertinent. Repetitive nerve stimulation at slow rates resulted in a slight decline in MAP amplitude, but at rapid rates facilitation of up to $140 \%$ occurred (Fig. 3). This phenomenon is seen in patients with myasthenia gravis only when there is an associated defect in the acetylcholine release mechanism (Brown and Johns, 1969; Takamore, 1971).

What is the explanation for curare sensitivity in these disorders? The defect of neuromuscular transmission in myasthenia gravis is complex.
The diminished size of acetylcholine quanta is thought to be due to a defect in their packaging or formation (Elmqvist et al., 1964) and, in addition, there is altered end plate sensitivity to acetylcholine (Grob et al., 1966).

Excessive curare-sensitivity has been reported in the myasthenic syndrome sometimes associated with carcinoma (Lambert et al., 1961). In our series the greatest degree of curare sensitivity seems to be associated with defective acetylcholine release, either in the Eaton-Lambert syndrome or in the occasional case of myasthenia gravis exhibiting evoked muscle action potential facilitation at rapid rates of nerve stimulation. While quanta can be released by a nerve impulse (so that loss of strength in the limb may not be evident), the undue curare sensitivity might be due to a lower than normal concentration of acetylcholine within the neuromuscular junction between periods of active neuromuscular transmission when the arrival of the nerve impulse results in acetylcholine release. Indeed, microelectrode studies in the Eaton-Lambert syndrome reveal a reduction in spontaneous acetylcholine quanta release (Elmqvist and Lambert, 1968). This could be the counterpart to the resistance to curare which can be induced in normal subjects by raising the acetylcholine concentration through repetitive nerve stimulation during its injection.

Such an explanation for curare sensitivity can be applied to the more complex block of myasthenia gravis: while inadequate jets of acetylcholine, released by nerve impulse, might result in the weakness, acetylcholine concentration within the synaptic space between impulses of neuromuscular transmission may be too low to compete with the curare. Thus, if ocular myasthenia with generalized curare sensitivity be considered, there could be asymptomatic widespread reduction in acetylcholine released spontaneously within the neuromuscular spaces with deficient transmission of acetylcholine in the active state confined to the extraocular muscles.

The possibility that the altered curare sensitivity in myasthenic disorders is due to postjunctional changes must also be considered. Since the integrity of the post-junctional membrane is dependent upon acetylcholine release, it is equally possible that the binding of curare is 
altered or that the structural changes in the postjunctional membrane in myasthenic disorders are in some way responsible for the altered sensitivity.

We wish to thank Mr P. Smith for technical assistance, Miss M. Stevenson for secretarial assistance, and Mr E. Stanley for help with statistical analysis. We are grateful to Dr F. R. Ellis and Dr D. J. Aidley for helpful advice and to $\operatorname{Dr} D$. A. Shaw for permission to study his patients. The work was supported by Grant 17912 from the Medical Research Council.

\section{REFERENCES}

Bennett, A. E., and Cash, P. T. (1943). Myasthenia gravis. Curare sensitivity; a new diagnostic test and approach to causation. Archives of Neurology and Psychiatry, 49, 537547.

Brown, J. C., and Johns, R. J. (1969). Clinical and physiological studies of the effect of guanidine on patients with myasthenia gravis. Johns Hopkins Medical Journal, 124, 1-8.

Brown, J. C., Charlton, J. E., and White, D. J. K. (1975). A regional technique for the study of sensitivity to curare in human muscle. Journal of Neurology, Neurosurgery, and Psychiatry, 38, 18-26.

Elmqvist, D., Hofmann, W. W., Kugelberg, J., and Quastel, D. M. J. (1964). An electrophysiological investigation of neuromuscular transmission in myasthenia gravis. Journal of Physiology, 174, 417-434.
Elmqvist, D., and Lambert, E. H. (1968). Detailed analysis of neuromuscular transmission in a patient with the myasthenic syndrome sometimes associated with bronchogenic carcinoma. Mayo Clinic Proceedings, 43, 689-713.

Feldman, S. A., and Tyrrell, M. F. (1970). A new theory of the termination of action of the muscle relaxants. Proceedings of the Royal Society of Medicine, 63, 692-695.

Grob, D., Johns, R. J., and Harvey, A. M. (1956). Studies in neuromuscular function. 6. Effect of anticholinesterase compounds, d-tubocurarine, and decamethonium in patients with myasthenia gravis. Bulletin of the Johns Hopkins Hospital, 99, 219-238.

Grob, D., Namba, T., and Feldman, D. S. (1966). Alterations in reactivity to acetylcholine in myasthenia gravis and carcinomatous myopathy. Annals of the New York Academy of Science, 135, 247-275.

Lambert, E. H., Rooke, E. D., Eaton, L. M., and Hodgson, C. H. (1961). Myasthenic syndrome occasionally associated with bronchial neoplasm: neurophysiologic studies. In Myasthenia Gravis, pp. 362-410. Edited by H. R. Viets. Thomas: Springfield, Ill.

Otsuka, M., and Endo, M. (1960). The effect of guanidine on neuromuscular transmission. Journal of Pharmacology and Experimental Therapeutics, 128, 273-282.

Paton, W. D. M. (1961). A theory of drug action based on the rate of drug-receptor combination. Proceedings of the Royal Society, B, 154, 21-69.

Pelikan, E. W., Tether, J. E., and Unna, K. R. (1953). Sensitivity of myasthenia gravis patients to tubocurarine and decamethonium. Neurology (Minneap.), 3, 284-296.

Rowland, L. P., Aranow, H., Jr, and Hoefer, P. F. A. (1961). Observations on the curare test in the differential diagnosis of myasthenia gravis. In Myasthenia Gravis, pp. 411-434. Edited by H. R. Viets. Thomas: Springfield, Ill.

Takamori, M., and Gutmann, L. (1971). Intermittent defect of acetylcholine release in myasthenia gravis. Neurology (Minneap.), 21, 47-54. 